\title{
Multiphysics Study of Infrared Thermography (IRT) Applications
}

\author{
Z Andleeb1, S Malik', G Hussain', H Khawaja 2,6*, \\ J Roemer ${ }^{3}$, G Boiger ${ }^{4}$, M Moatamedi5,6 \\ 1. Ghulam Ishaq Khan Institute of Engineering Sciences and \\ Technology, Pakistan \\ 2. UiT-The Arctic University of Norway \\ 3. AGH University of Science and Technology, Krakow, \\ Poland \\ 4. ZHAW Zurich University of Applied Sciences \\ 5. Oslo Metropolitan University, Norway \\ 6. Al Ghurair University, UAE
}

\begin{abstract}
The paper reviews thermographic and vibrothermography applications such as cold climate operations, determine the temperature profile of steel samples under tensile testing and perform composites Non-Destructive Testing (NDT). This review paper discusses studies, where IR thermography has been used effectively in research and development projects at the UiT The Arctic University of Norway and AGH UST. The applications discussed in this work are to determine:

- Thermal conductivity and heat transfer coefficient of freshwater and marine ice

- An industrial solution for detecting icing

- Relative required insulation (IREQ) of apparels

- Variation of tensile strength and surface temperature of steel samples under tensile testing under cold temperatures

- Vibrothermography for Non-Destructive Testing (NDT) of composites
\end{abstract}

\section{INTRODUCTION}

Infrared thermography is the science of detecting infrared energy emitted from an object. Literally, infrared thermography means "beyond red temperature image". IR thermography being a remote non-contact/non-destructive means of testing is perfectly suitable for tests in extreme environments. In addition, it is fast, reliable and detailed. Due to the advantages offered by IR thermography, it is extremely popular in various industries. Infrared thermography (IRT) has a long history in industrial applications. Moreover, its use is increasing exponentially in research and development sectors. Academic and research institutions are finding IR thermography as one of the fundamental tools for teaching and research. 
Cold climate operations face several challenges. Recent activity in the Arctic Circle has encouraged researchers to study the various challenges. Thermography is one such technique that is used for this purpose - it exploits the infrared wavelengths of the electromagnetic spectrum region from $0.75 \mu \mathrm{m}$ to $1 \mathrm{~mm}$ [1]. Much like a visible light camera, an infrared camera uses a lens to focus the infrared light of different wavelengths emitted (thermal radiation) by all objects in view, which is converted into an electronic signal by infrared detectors. The signal is further processed digitally to create a thermal image. The basic set-up of thermography is illustrated in Figure 1. The rate of energy emitted as thermal radiation is highly dependent on the surface temperature. Small temperature changes in the test specimens generate visible thermal readings that can be successfully captured by infrared detectors to yield thermogram.

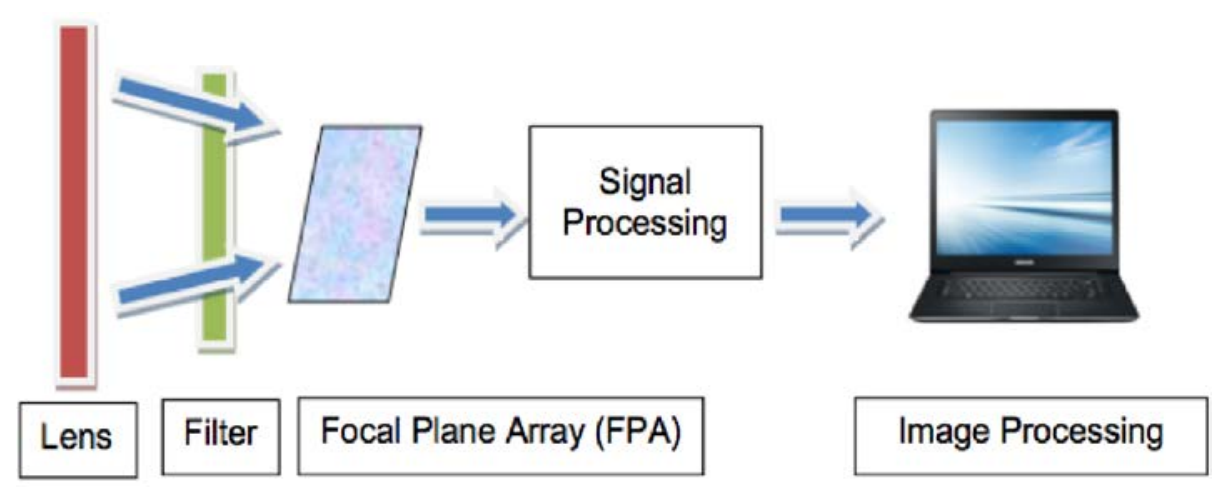

Figure 1: Basic set-up of thermography testing

In the cold environment the long-term exposure of the superstructures to marine icing can cause rapid ice accretion, which can be hazardous for both human and machine safety [2]. Icing on ships and offshore structures is caused by atmospheric sources and sea spray, with sea spray being the major contributor to icing [3].

The radiative emissivity of ice varies with the wavelength. Figure 2 shows how the emissivity of pure ice made from distilled water varies with wavelength [4]. It shows that the value of ice emissivity varies from 0.965 to 0.995 in the range of $4 \mu \mathrm{m}$ to $13 \mu \mathrm{m}$ wavelengths which means that ice has high radiative emittance in the thermal and the far IR ranges

In cold environments, thermal insulation is the general term, commonly used for garments that provide adequate protection against the cold and to prevent heat loss from the human body. It accounts for the effect of layers, fit, drape, coverage and shape. Thermal insulation varies with fabrics/clothing, substandard garments may reduce the thermal insulation more significantly, due to laundering and wear, than in the case of high-quality products [5]. There are two well-accepted standards to define clothing thermal insulation/thermal comfort: British Standard - EN 342 and ISO 11079:2007 (E) [6]. 


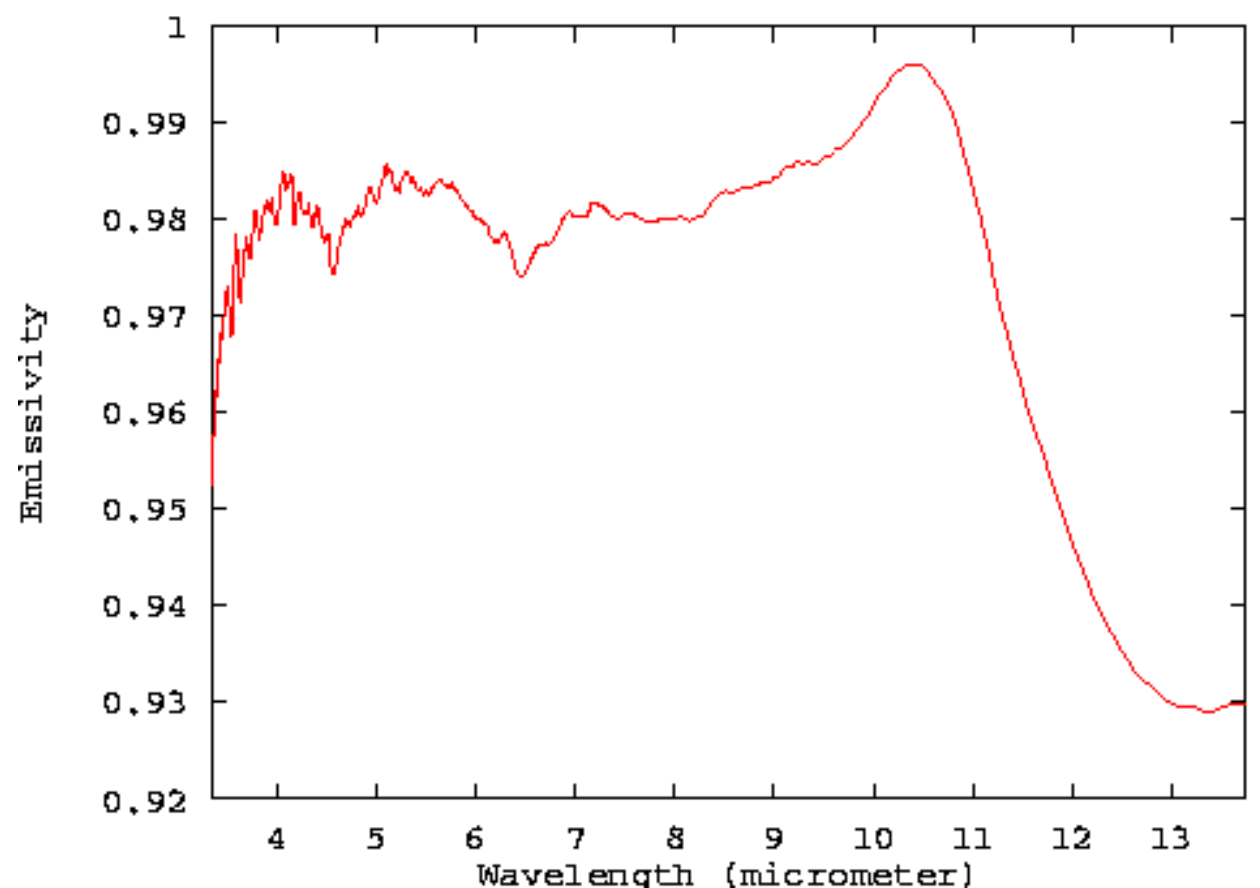

Figure 2: Emissivity of ice with wavelength ( $\mu \mathrm{m})[4]$

The thermoelastic effect of a material is illustrated by the expansion of a heated solid and the reciprocal effect. If the applied stress is homogeneous, the same temperature change will occur throughout the specimen. On the other hand, a non-homogeneous stress applied will set up a temperature gradient in the material. The heat transfer into or out of the material produces an additional non-elastic strain. In general, a conversion of mechanical energy into heat will be a result of the thermoelastic heat transfer and the associated non-elastic behavior [7]. The application of a periodically varying non-homogeneous stress will produce a time varying temperature gradient within an element of the material. Stress inhomogeneities give rise to heat currents, which increase entropy, and an increase of entropy is inevitably associated with the generation of heat [8].

Composite materials are widely used in many engineering applications. Unlike the 'standard' materials, composites are prone to specific types of damages like delamination. This type of damage can be completely invisible from the outside, therefore advanced NDT methods are needed. The ultrasonic testing is widely used for composite NDT; however, this method can be slow, and sometimes very hard to implement, especially for materials with complex geometry. Therefore, there is still a need for new robust techniques for composite NDT. 


\section{DETERMINATION OF THERMAL CONDUCTIVITY AND HEAT TRANSFER COEFFICIENT OF FRESHWATER AND SEAWATER WITH THERMOGRAPHY}

Compared with freshwater ice, whose physical properties are well known since the early 1900 s, seawater ice is a comparatively complex substance. The transition of seawater ice to a completely solid mixture of pure ice and solid salts is completed only at extremely low temperatures rarely encountered in nature [9].

The physical properties of sea ice are thus strongly dependent on salinity, temperature and time [9]. Many of these properties are still not fully understood or accurately known, particularly those important for the understanding of a natural ice cover. The coefficient of thermal conductivity and overall heat transfer coefficient is an important term in the calculation of the heat energy content of the ice cover.

The coefficient of thermal conductivity (also known as thermal conductivity) determines the amount of heat transfer based on the temperature difference between two points. Rashid et al. [10] studied thermal properties of ice by placing a piece of ice taken from a cold environment into the ambient and allowing it to warm under room temperature conditions. These conditions established thermal gradients within the ice cube. Following important features were observed: variation in temperature on the ice surface and increase in the temperature of the ice cube.

As according to the mechanism of heat transfer, thermal conductivity of ice and its cubic geometry is responsible for setting up variation in temperature on the ice cube surface. The second feature is associated with the overall heat transfer coefficient. This feature determines how rapidly heat is being released (or absorbed as in this case) by the ice surfaces from the surroundings.

The underlying physics of heat transfer through conduction in a solid medium can be solved with the heat equation [11] as given in Equation (1),

$$
\begin{gathered}
\frac{\partial^{2} T}{\partial t^{2}}=\alpha\left(\frac{\partial^{2} T}{\partial x^{2}}+\frac{\partial^{2} T}{\partial y^{2}}+\frac{\partial^{2} T}{\partial z^{2}}\right) \\
\alpha=\frac{k}{\rho c} \\
-k \frac{\partial T s}{\partial x}=h\left(T_{\infty}-T_{S}\right)
\end{gathered}
$$

where $x, y$ and $z$ refer to spatial positions (m) in three dimensions and $\alpha$ is the thermal diffusivity term $\left(\mathrm{m}^{2} / \mathrm{s}\right)$ as given in (2), $T_{s}$ is the surface temperature $(\mathrm{K}), T_{\infty}$ is the surrounding temperature $(\mathrm{K})$ and $h$ is convective heat transfer coefficient $\left(\mathrm{W} /\left(\mathrm{m}^{2} . \mathrm{K}\right)\right)$.

To solve Equation (1), the boundary, and the initial conditions are required. The convective boundary conditions [12] are applied on each external surface of the cubical geometry as given in Equation (3). Similar conjugate heat transfer problem study was performed by Leyli et al. [13] where heat transfer and forced convection was studied with thermography.

Rashid et al. [10] work focused on the determination of the coefficient of thermal conductivity and the overall heat transfer coefficient, using infrared experimental technique [14-16] and Forward-Time Central-Space (FTCS) Finite Difference Method (FDM) method using MATLAB ${ }^{\circledR}$ [17]. The discretized heat equation that is solved and pre-processed in MATLAB ${ }^{\circledR}$ is shown in equation 4. 


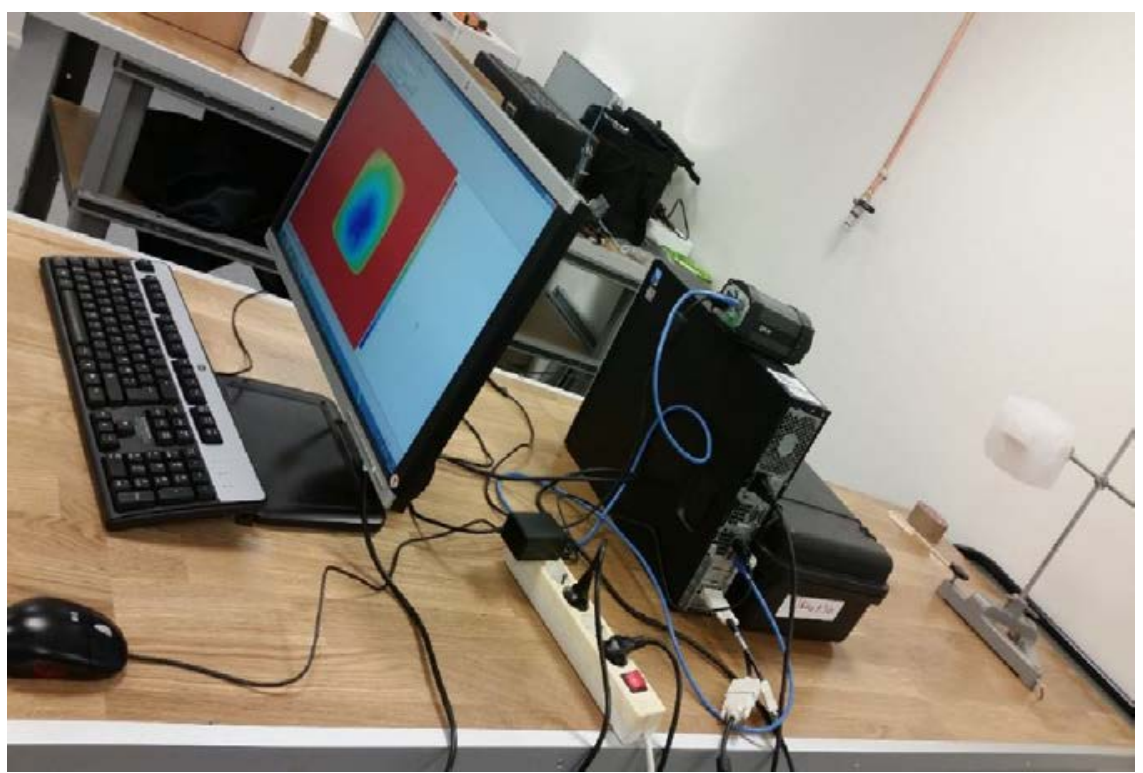

(a)

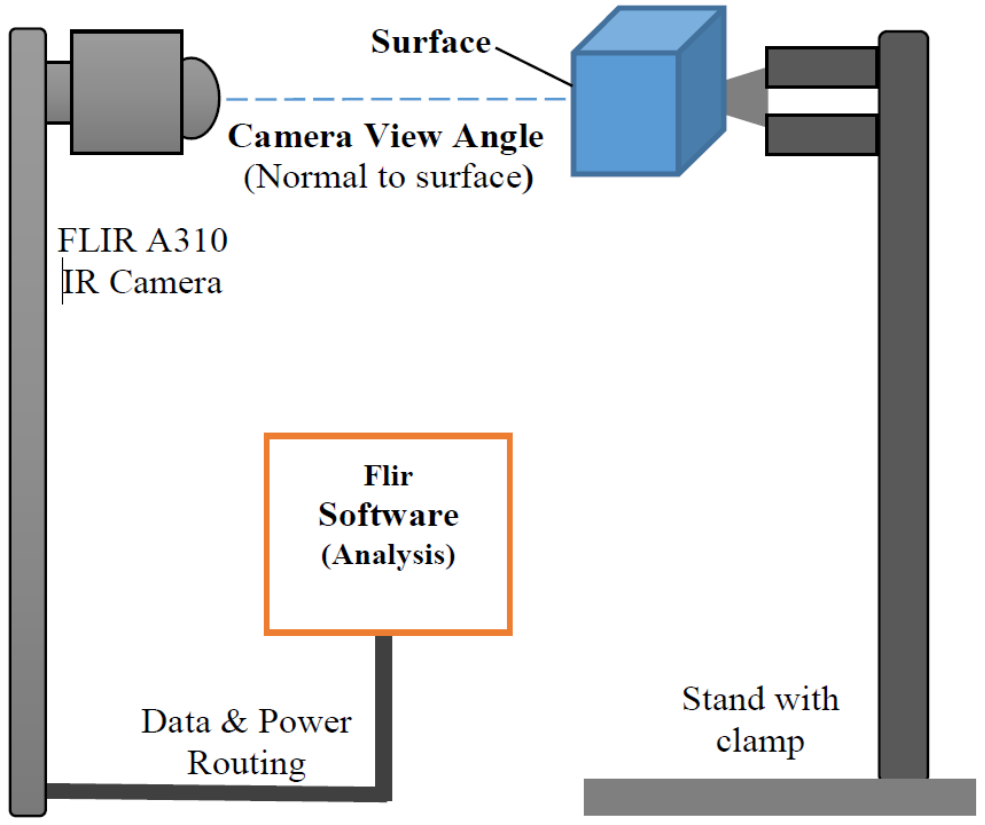

(b)

Figure 3. Ice cube infrared imaging test rig photo (a) and schematic view (b) 


$$
\begin{aligned}
T_{i, j, k}^{t+1}= & T_{i, j, k}^{t}+\alpha \frac{\left(T_{i+1, j, k}^{t}-2 T_{i, j, k}^{t}+T_{i-1, j, k}^{t}\right)}{(\Delta x)^{2}} \Delta t \\
& +\alpha \frac{\left(T_{i, j+1, k}^{t}-2 T_{i, j, k}^{t}+T_{i, j-1, k}^{t}\right)}{(\Delta y)^{2}} \\
& +\alpha \frac{\left(T_{i, j, k+1}^{t}-2 T_{i, j, k}^{t}+T_{i, j, k-1}^{t}\right)}{(\Delta z)^{2}}
\end{aligned}
$$

where superscript $t$ and subscript $i, j, k$ refers to time and position, respectively for a value of nodal temperature. $\Delta t$ is a timestep size (s) and $\Delta x, \Delta y, \Delta z$ are the differences in the spatial positions of the temperature nodes. Results obtained from MATLAB ${ }^{\circledR}$ simulations are shown in figure 4 (a).
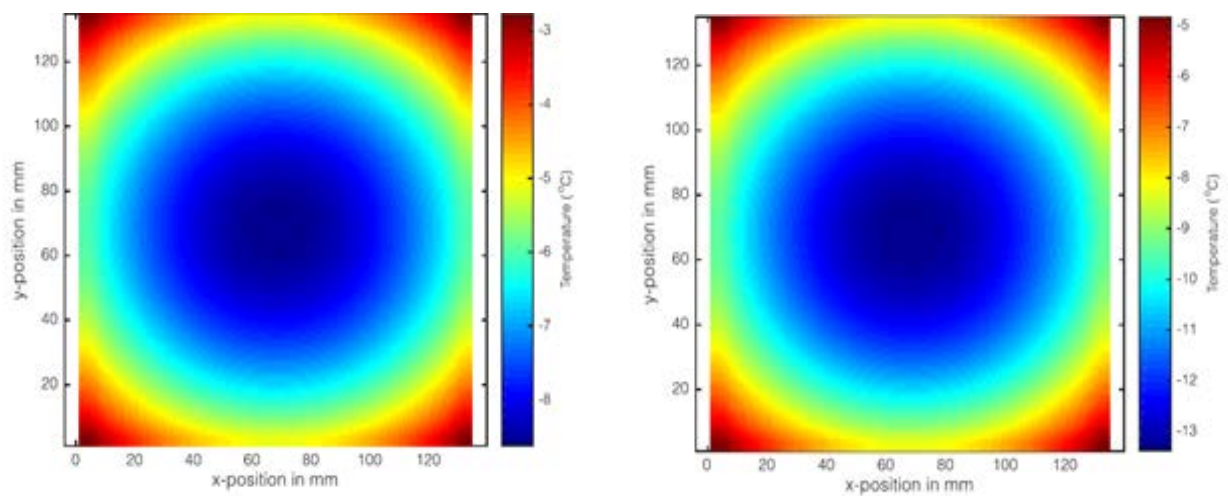

(a) Finite Difference Method Matlab® Simulations
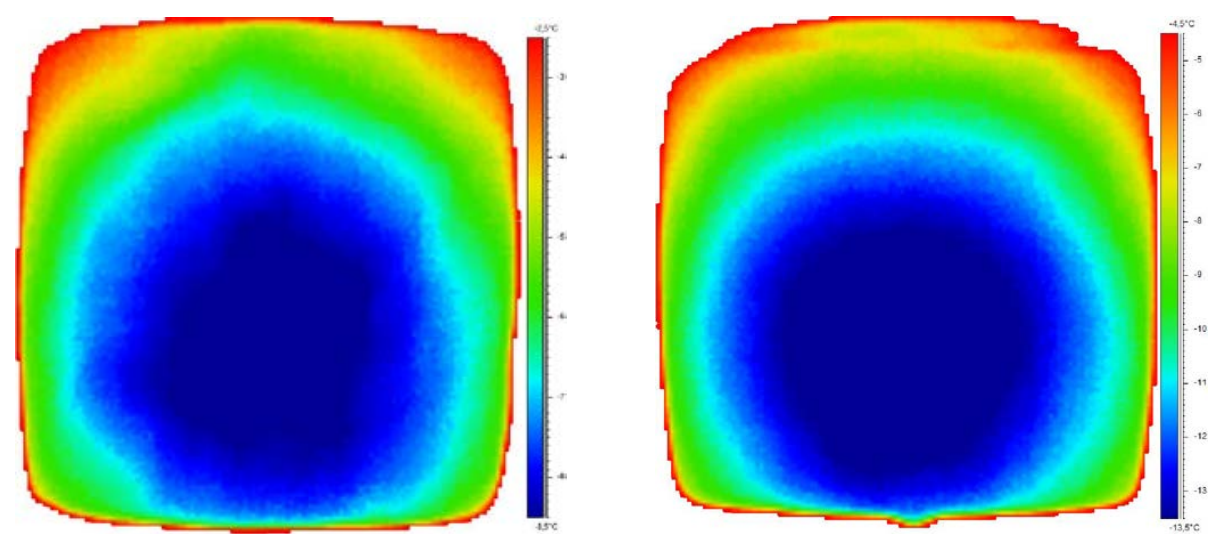

(b) Infrared Image

Figure 4. Experimental vs simulation results of temperature of freshwater lce cube after 2000s (left) Sea water lce cube after 2000s (right)

Infrared imaging experiments were performed using an A310 FLIR $₫$ infrared camera [18]. The data was analyzed by FLIR ${ }^{\circledR}$ research software [19]. The actual experimental setup is shown in Figure 3a. The schematic of the experimental setup is shown in Figure 3b. 


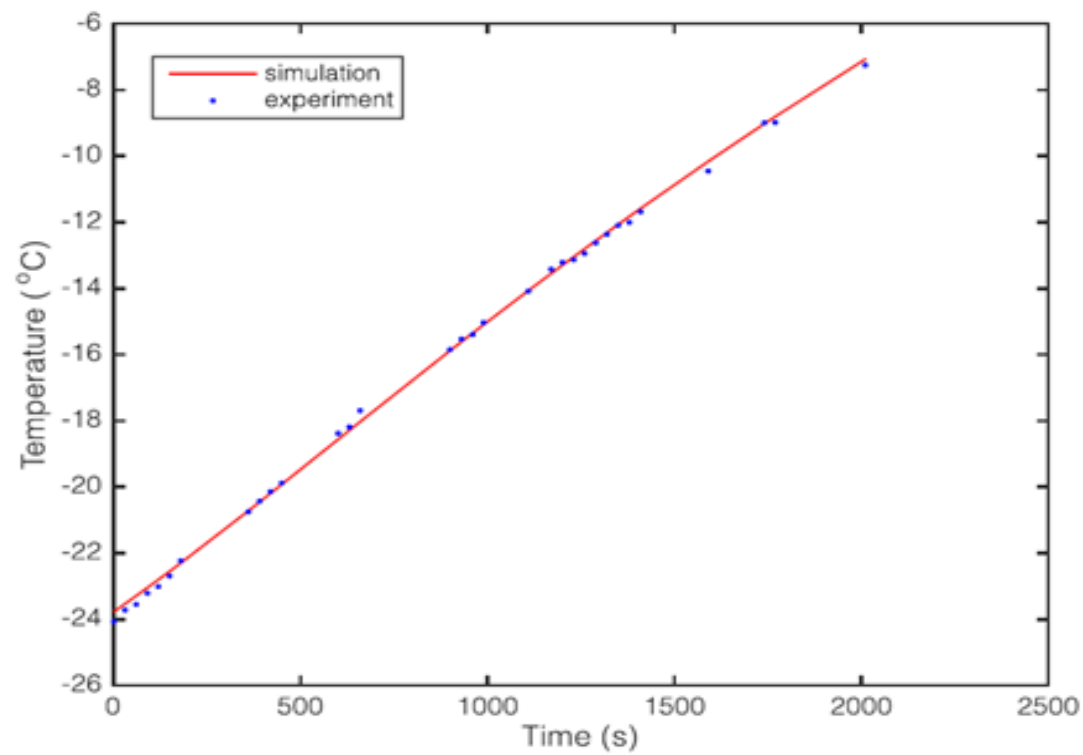

Figure 5. Variation in temperature with time for freshwater ice cube

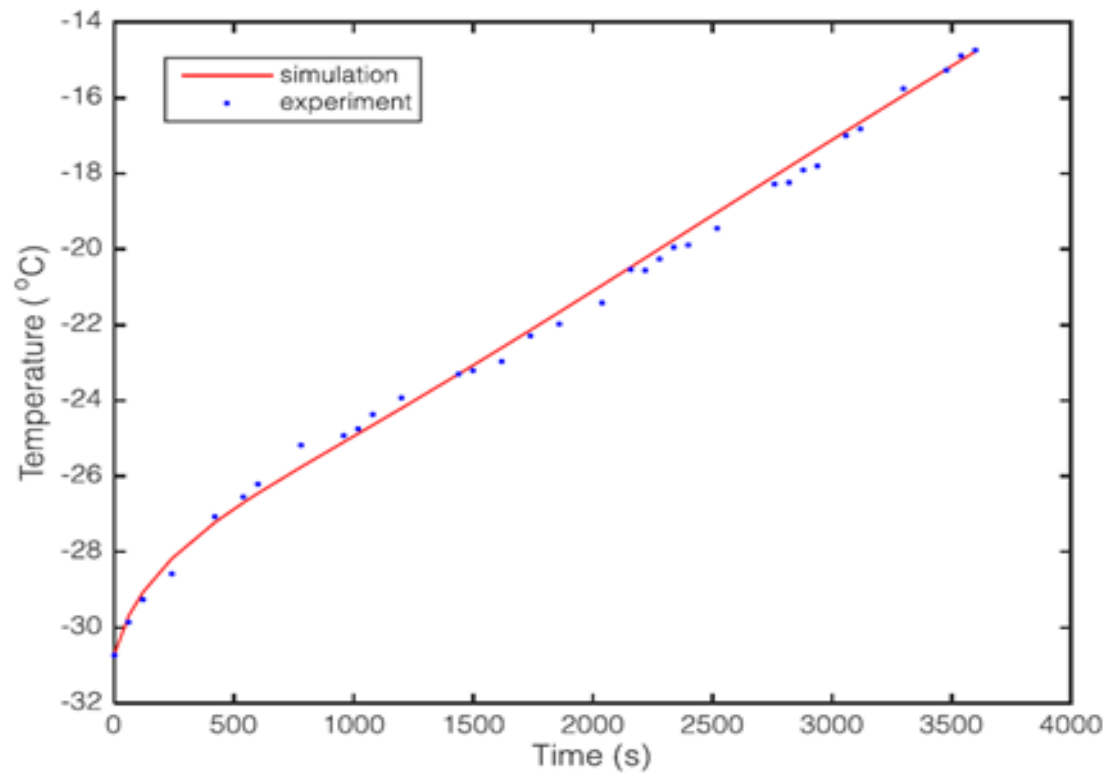

Figure 6. Variation in temperature with time for saline water ice cube 
The sample of ice was taken out of the freezer at $-31{ }^{\circ} \mathrm{C}$ and was allowed to warm under room conditions. The dimensions of the ice cube were $13.5 \times 13.5 \times 10 \mathrm{~cm}^{2}$. As ice cube sample warmed, temperature profiles formed on the surface of the ice, which were recorded using an infrared imaging camera as shown in figure 4 (b). The experimentation results revealed the variations in surface temperature over time. The experiments were repeated with fresh water and saline ice cubes.

The results from both MATLAB ${ }^{\circledR}$ simulations and Infrared imaging technique as shown in figure 4, 5 and 6 revealed that the fresh water ice cube samples has an average conductivity of about $2.35(\mathrm{~W} /(\mathrm{m} . \mathrm{K}))$ in a temperature range of about $-30^{\circ} \mathrm{C}$ to $0^{\circ} \mathrm{C}$, which is in agreement with the literature. For saline ice the average conductivity dropped significantly 0.8 (W/(m.K)) in the same temperature range.

The average value of the overall heat transfer coefficient of freshwater ice was found to be about $9.2\left(\mathrm{~W} /\left(\mathrm{m}^{2} . \mathrm{K}\right)\right)$. The average value of the overall heat transfer coefficient of saline ice was found to be $4.2\left(\mathrm{~W} /\left(\mathrm{m}^{2} . \mathrm{K}\right)\right)$, approximately half of the freshwater ice.

This work illustrates IR imaging could be introduced into the industry as a quick, remote and effective method for determining thermal conductivity and overall heat transfer coefficient of fresh and marine ice. As thermal conductivity is related to density, this method can be used to predict ice density on the seabed in winters.

\section{AN INDUSTRIAL SOLUTION FOR DETECTING ICING}

Various empirical models have been developed to predict the marine icing phenomenon. Marine icing can accrete on the ship's structure rapidly, causing a potential safety hazard. Currently, various methods are being used to remove icing (de/icing) present on the ships. These involve electrical, mechanical, chemical and manual methods [20]. Once marine icing has accreted on the ships, more energy is required to remove it. Consequently, if ice mitigation is performed prior to the marine icing phenomenon, it could save more energy and time.

Rashid et.al [16] determined marine ice thickness by measuring the surface temperature of the marine icing samples. They applied heat energy to an icing sample for a maximum period of 380 seconds. The surface temperature of the icing sample was monitored with FLIR ${ }^{\circledR}$ T1030sc IR camera [18]. IR frames were captured from 10 to 380 second. Heat energy was supplied underneath the icing sample, using an electric heating element with temperature control that is directly in contact with the icing sample. Initially, the icing sample and the heating source were kept in a thermal equilibrium state. As soon as heat energy was supplied from a heating source, a thermal gradient was established; with high temperature on the ice surface exposed to the metal plate of the heating source and low temperature on the open top surface of the cube. In order to attain a thermal equilibrium state, the heat energy was transmitted from the heating source to the icing sample along the temperature gradient. This is a typical heat transfer phenomenon between the two physical masses as shown in Figure 5, which are in contact and possess a non-equilibrium thermal state.

The experimentation process is shown in Figure 6. The marine icing samples were prepared by freezing seawater in the icing container. Controlled laboratory tests were performed to measure the salinity of the sea water sample used for experimentation. The salinity of seawater was $46.4 \pm 0.9 \mathrm{~g} / \mathrm{l}$. 
The icing container was attached to the flat plate of the heating element. The top surface of the icing container was exposed, to measure the surface temperature of the icing sample. Icing samples of different thicknesses, such as $5 \mathrm{~mm}, 10 \mathrm{~mm}$ and $15 \mathrm{~mm}$, were frozen inside the icing containers. Positive temperature coefficient (PTC) resistive heating elements were used to provide heating to the icing samples. There was direct contact between the icing samples and the plate of the heating element. The walls of the icing container provided thermal insulation of the heating elements from all sides, excluding the top surface. Hence, the maximum possible heat transfer was allowed from the top surface of the heating elements. The icing samples were taken out of the cold room and put inside the cold box, along with the hardware control unit. The internal temperature of the cold box was adjustable up to $-55^{\circ} \mathrm{C}$. The experimentation was performed at different negative temperatures inside the cold box from $-15{ }^{\circ} \mathrm{C}$ to $-30{ }^{\circ} \mathrm{C}$. The infrared camera was mounted on a stand at an angle of $90^{\circ}$ to observe the thermal behavior of the icing samples in the containers when heated from underneath.

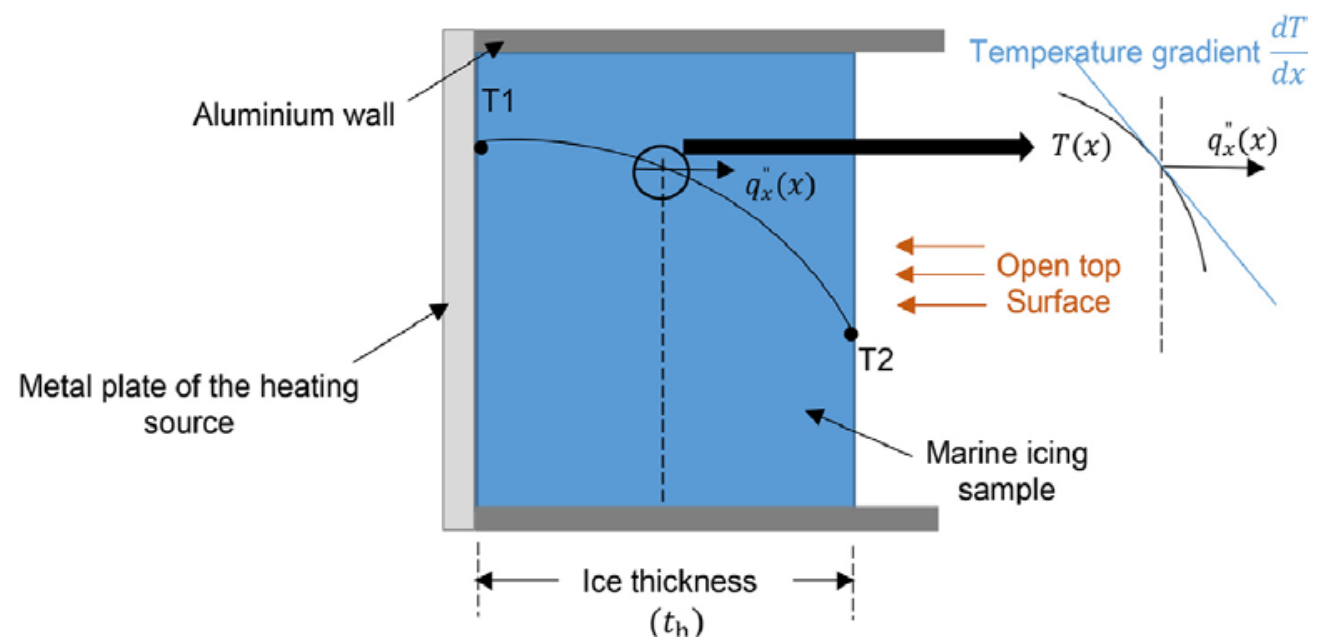

Figure 5: Relationship between heat flux, temperature gradient and coordinate system within an icing sample [21]

The results showed distinguishable temperature profiles with different thicknesses of ice as shown in Figure 7. In these temperature profiles, three parameters were identified, which can be correlated with ice thickness: the time to respond, the time taken by the ice to reach a certain temperature and the rate of surface temperature change.

Several approaches, from analytical to computational models, are possible to evaluate the reliability and vulnerability of the structural systems.

For different initial temperatures, the time to respond was observed to be unique for a specific thickness of the ice. This parameter is independent of the initial temperature and provides an indication about the thickness of the icing sample. The methodology presented in the paper requires an average time of 180-380 seconds to indicate the ice thickness levels. 
Hence, this methodology can be applied for detecting marine ice thickness. It can contribute to automated anti-icing/de-icing systems to remove and/or mitigate marine icing on ships and superstructures operating in a cold climate.

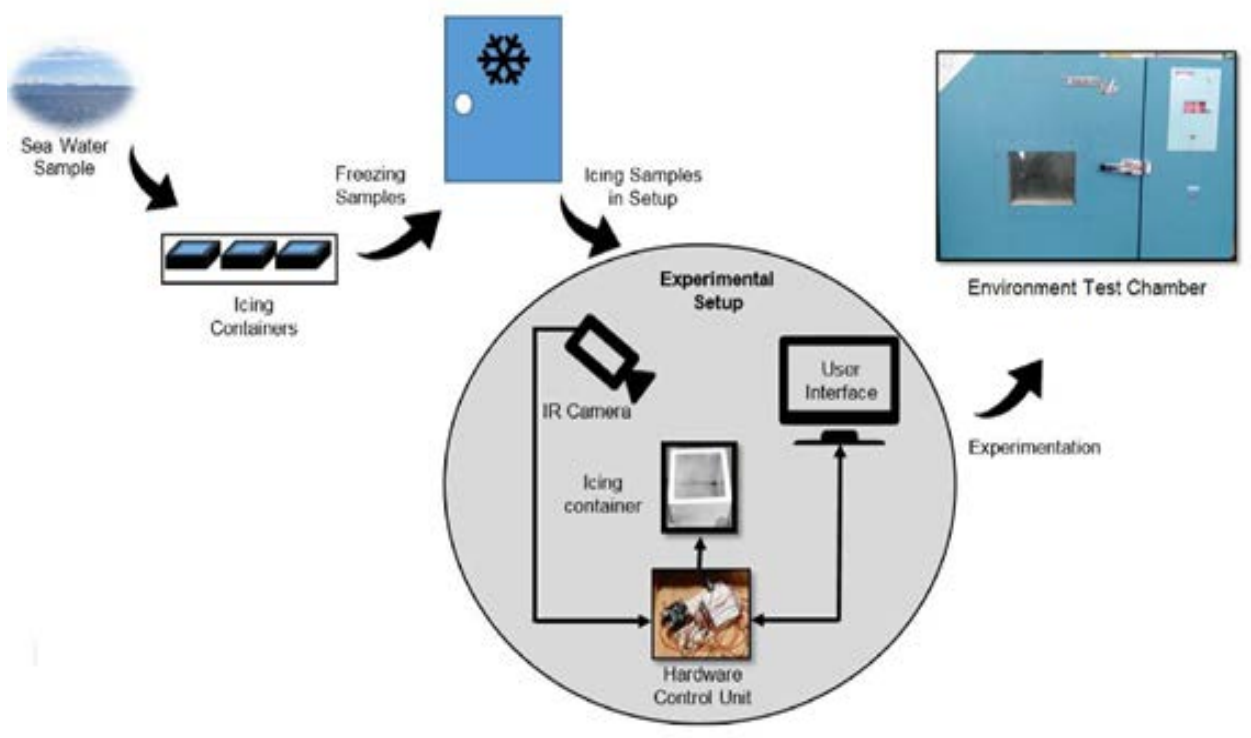

Figure 6: Experimentation process

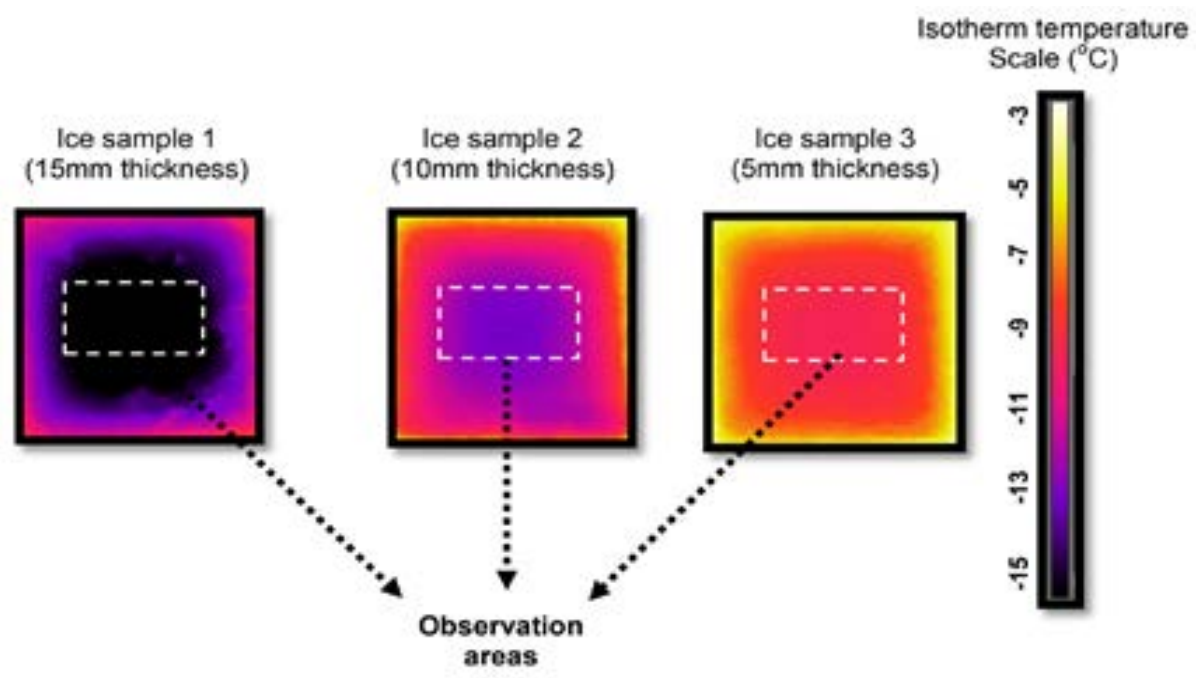

Figure 7: IR images of the surface area of the ice samples 


\section{DETERMINATION OF RELATIVE REQUIRED INSULATION IREQ OF APPARELS WITH THERMOGRAPHY}

The sense of cold develops due to the increase in heat loss from the human body [22]. Excessive cold can be a health hazard, since excessive heat loss from the body may result in hypothermia/frostbite. Decreased body temperature due to heat loss also affects the physical, manual and perceptive performance of individuals. Therefore, protective measures are taken through clothing that controls and regulates heat loss. Clothing is a protective means for thermal insulation. Clothing and garments used in cold climates should have sufficient insulation to maintain the thermal balance of the body. The required clothing insulation (IREQ) is calculated on the basis of the hypothesis concerning the heat flow by conduction, convection, radiation and evaporation.

The IREQ represents the resultant clothing insulation required in a cold environment to maintain the body in a state of thermal equilibrium at an acceptable level of body and skin temperatures. IREQ measures the cold stress, combining the effects of air temperature, mean radiant temperature, relative humidity, and air velocity for a defined level of metabolic rate. It analyzes the effects of the cold environment and the metabolic rate on the human body also dealing with the requirement of particular clothing insulation and the subsequent selection of clothing to be used under actual conditions.

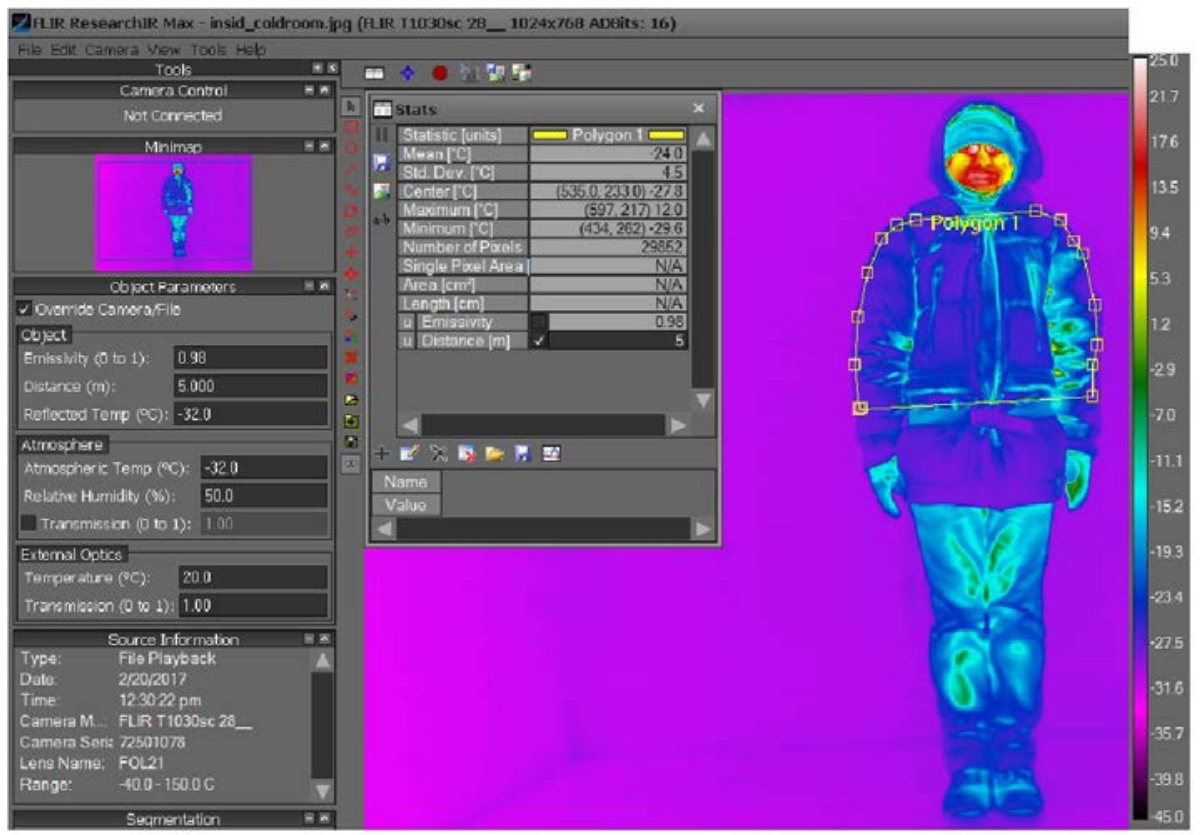

Figure 8: IR image analyzed with FLIR ResearchIR Max® software (image taken in cold room with FLIR $® 1030$ sc camera [17-18])

Tanveer et.al. [23] performed experiments to capture thermal images of different clothing in cold room and room temperature using a thermographic camera and analysis software as shown in Figure 8 and 9. 


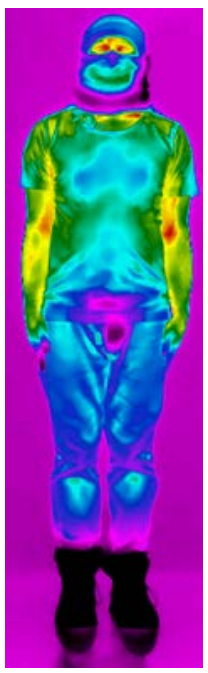

(I) Outside cold room

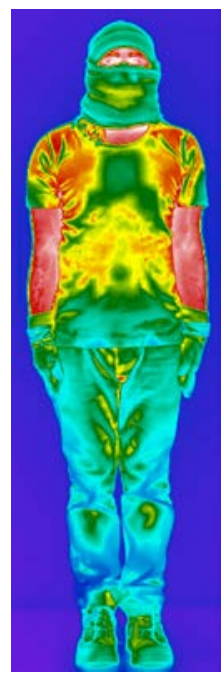

(II) Inside cold room

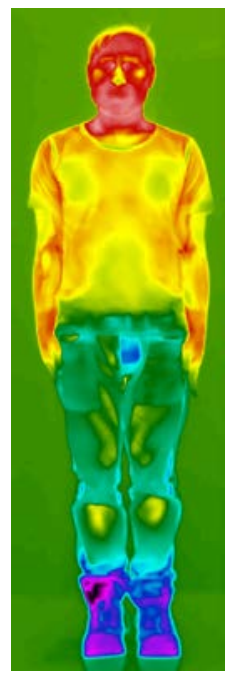

(III) Outside cold room

(a) Subject is wearing jeans, t-shirt, underwear, surface temperature without additional clothing $\left(\right.$ Ts $\left({ }^{\circ} \mathrm{C}\right)$

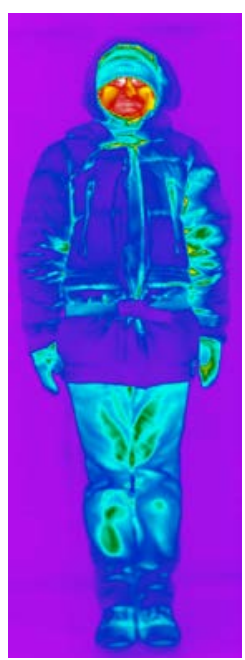

(IV) Outside cold room

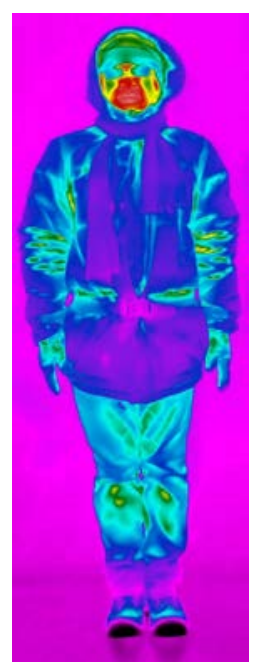

(V) Inside cold room

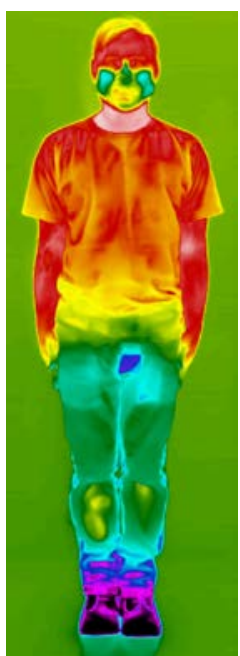

(VI) Outside cold room (b) subject wearing Jean Paul ${ }^{\circledR}$ winter jacket, socks and shoes, surface temperature with additional clothing $\left(T c\left({ }^{\circ} \mathrm{C}\right)\right.$

Figure 9. Infrared images of the subject

Thermal insulation is the general term, commonly used for garments that provide adequate protection against the cold and prevent heat loss from the human body. Thermal insulation varies with fabrics/clothing and Tanveer et.al. [23] tested with various clothes and garments.

They calculated surface temperatures with and without winter jackets, and their respective IREQ from equation 4. 


$$
\operatorname{IREQ}=\frac{T_{S}-T_{C}}{R+C}\left({ }^{\circ} \mathrm{Cm}^{2} W^{-1}\right)
$$

where $T_{s}$ is the mean surface temperature with basic clothing in ${ }^{\circ} \mathrm{C}$ and $T_{c}$ is the mean surface temperature with additional clothing in ${ }^{\circ} \mathrm{C}$. In this study, the combined value of heat through radiation and convection $\mathrm{R}+\mathrm{C}$ is assumed to be $55 \mathrm{Wm}^{-2}$.

Table 1: Surface temperatures with and without winter jackets, and respective IREQ

\begin{tabular}{llll}
\hline $\begin{array}{l}\text { Additional } \\
\text { clothing type }\end{array}$ & $\begin{array}{l}\text { Surface temperature Surface temperature } \\
\text { without additional } \\
\text { clothing }-T_{S}\left({ }^{\circ} \mathbf{C}\right)\end{array}$ & $\begin{array}{l}\text { with additional clothing } \\
-T_{C}\left({ }^{\circ} \mathbf{C}\right)\end{array}$ & $\begin{array}{l}\boldsymbol{T}_{\boldsymbol{s}}-\boldsymbol{T}_{\boldsymbol{c}} \\
\boldsymbol{R}+\boldsymbol{C}\left({ }^{\circ} \mathbf{C m}^{2} \boldsymbol{W}^{-\mathbf{1}}\right)\end{array}$ \\
\hline Levi's ${ }^{\circledR}$ & 28.0 & -24.7 & 0.958 \\
Stormberg${ }^{\circledR}$ & 27.3 & -33.6 & 1.107 \\
Kraft ${ }^{\circledR}$ & 29.1 & -28.5 & 1.047 \\
Jean Paul ${ }^{\circledR}$ & 27.9 & -24.1 & 0.945 \\
Fjell Raven ${ }^{\circledR}$ & 28.0 & -26.8 & 0.996 \\
Winter Jackets & 28.0 & -27.54 & 1.01 \\
Average & & & \\
\hline
\end{tabular}

As from Tanveer et.al. [23] study, Stormberg ${ }^{\circledR}$ jacket is found to have relatively highest IREQ value. This study proved that infrared imaging can be used effectively to determine relative required insulation for clothing (IREQ).

\section{VARIATION OF TENSILE STRENGTH AND SURFACE TEMPERATURE OF STEEL SAMPLES UNDER TENSILE TESTING WITH COLD TEMPERATURE}

The uniaxial tensile test is one of the most fundamental types of material characterization test available. It works by continuously measuring the force required to elongate a test specimen by increasing increments of the pulling force, until the specimen fractures. The destructive test process measures a number of important material properties i.e. elasticity, plasticity, ultimate strength and maximum elongation of the material. Most importantly, it generates stress strain curve, which is a graphical measure of a material's mechanical properties.

In this work, Stange et.al. [24] studied thermal signature of the steel specimens (DIN 50125 Standard [25]) undergoing the tensile tests with the help of infrared thermography. They coated the steel specimens as shown in figure 11 with high emissivity paint and repeated the test under various surrounding temperatures such as $25^{\circ} \mathrm{C},-5^{\circ} \mathrm{C},-10^{\circ} \mathrm{C},-15^{\circ} \mathrm{C}$, and $-20^{\circ} \mathrm{C}$. The IR thermographic imaging was performed using the FLIR ${ }^{\circledR}$ T1030sc IR camera [18] and ResearchIR Max software [19]. The results were shown in Figures 12 and 13.

They observed heat generation, associated with the thermoelastic effects, in the steel specimen undergoing tensile test with thermography. The authors suggested heat generation exhibited in the steel specimens in Figure 13 was not thermally isolated therefore there were thermal losses due to conduction and convection. 
Nonetheless the thermal images obtained via infrared thermography reflects qualitative visualization of the development of stresses as shown in Figures 12 and 13.
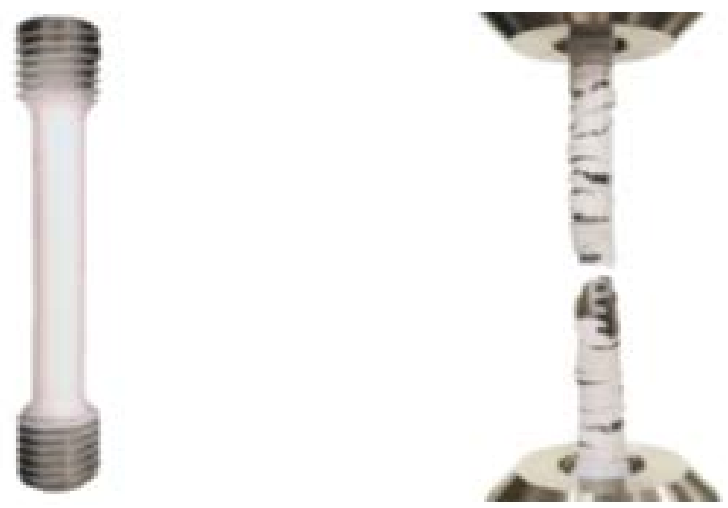

Figure 11: Painted steel Test Specimen
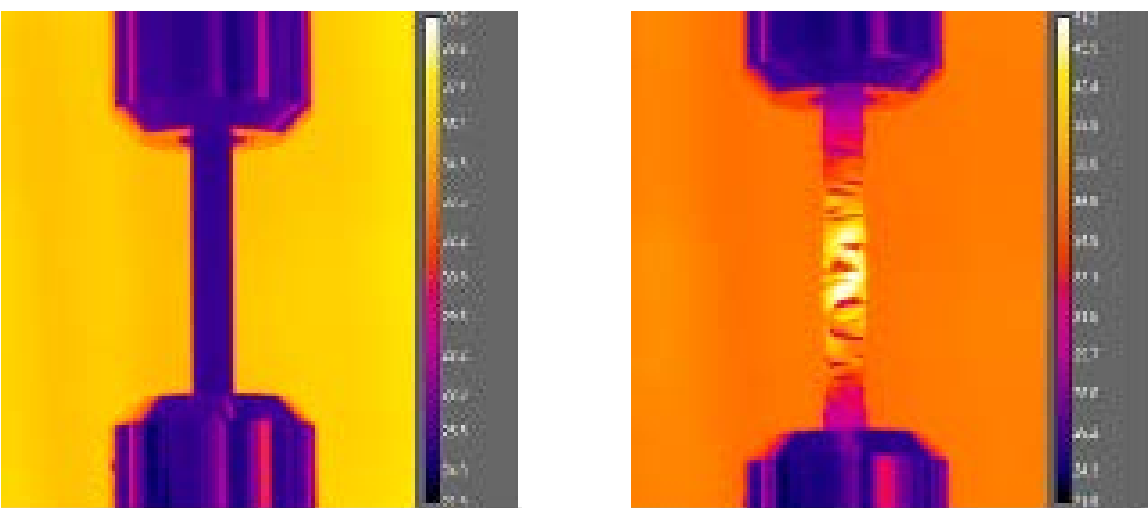

Figure 12: Infrared Thermography of standard steel sample

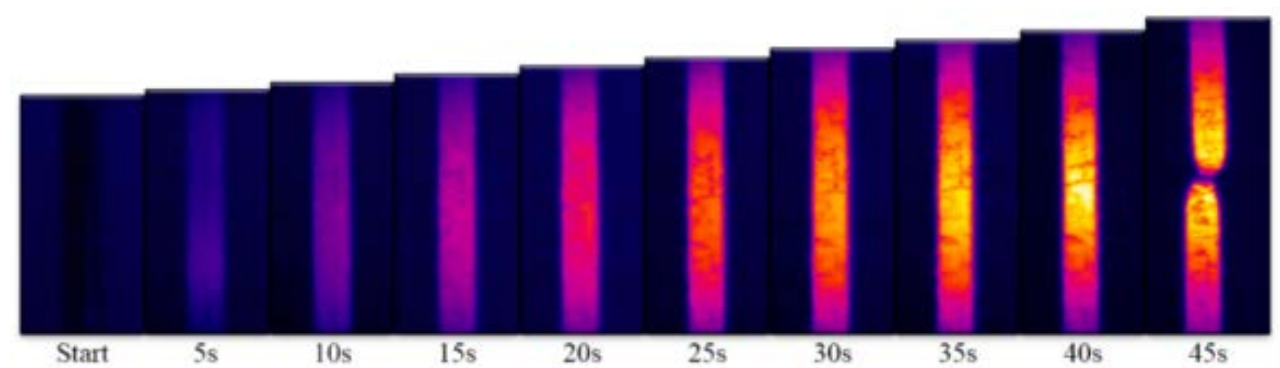

Figure 13: Qualitative visualization of stresses (frame 1-10)

They observed heat generation, associated with the thermoelastic effects, in the steel specimen undergoing tensile test with thermography. The authors suggested heat generation exhibited in the steel specimens in Figure 13 was not thermally isolated therefore there were thermal losses due to conduction and convection. 
Nonetheless the thermal images obtained via infrared thermography reflects qualitative visualization of the development of stresses as shown in Figures 12 and 13.

Table 2 presents the values of tensile strength and temperature change for each defined test temperature. The ultimate tensile stress exhibits a progressive increase with decreasing temperature. A maximum increase of $15 \mathrm{~N} / \mathrm{mm}^{2}$ was obtained at $-20^{\circ} \mathrm{C}$. The temperature difference in the specimen varied for each test temperature, but not in a specific pattern. The minimum temperature difference observed was $22.44^{\circ} \mathrm{C}$, and a maximum difference of $28.93^{\circ} \mathrm{C}$. The heat generation was approximately equal for all defined test temperatures, with an average temperature increase of $25.4^{\circ} \mathrm{C}$.

Table 2: Values of tensile strength and temperature change for each defined test temperature

\begin{tabular}{lllll}
\hline & $\begin{array}{l}\text { Ultimate Stress } \\
\left(\mathbf{N} / \mathbf{m m}^{2}\right)\end{array}$ & $\begin{array}{l}\text { Start } \\
\left({ }^{\circ} \mathbf{C}\right)\end{array}$ & $\begin{array}{l}\text { End }(\mathbf{T}) \\
\left({ }^{\circ} \mathbf{C}\right)\end{array}$ & $\begin{array}{l}\Delta \mathbf{T} \\
\left({ }^{\circ} \mathbf{C}\right)\end{array}$ \\
\hline Test $\left(25^{\circ} \mathrm{C}\right)$ & $462.28 \pm 5.514$ & 24.218 & 50.3 & 26.083 \\
& & 23.059 & 49.2 & 26.141 \\
Test $\left(-5^{\circ} \mathrm{C}\right)$ & $470.63 \pm 2.62$ & -8.614 & 14.292 & 22.906 \\
& & -8.937 & 13.84 & 22.777 \\
Test $\left(-10^{\circ} \mathrm{C}\right)$ & $471.29 \pm 2.69$ & -16.827 & 12.104 & 28.931 \\
& & -16.554 & 11.279 & 27.832 \\
Test $\left(-15^{\circ} \mathrm{C}\right)$ & $476.17 \pm 4.38$ & -17.356 & 8.077 & 25.433 \\
& & -17.428 & 5.015 & 22.442 \\
Test $\left(-20^{\circ} \mathrm{C}\right)$ & $477.37 \pm 1.46$ & -25.623 & 0.486 & 26.109 \\
& & -24.888 & 0.215 & 25.102 \\
Increase from & \multirow{2}{*}{15.09} & Average & & 25.376 \\
$25^{\circ} \mathrm{C}$ to $-20^{\circ} \mathrm{C}$ & & & & \\
\hline
\end{tabular}

Thermography is found to be an effective tool for measuring heat generation associated with the thermoelastic effects.

\section{VIBROTHERMOGRAPHY FOR NONDESTRUCTIVE TESTING OF COMPOSITES}

Composites are materials consisting of two or more different materials bounded into one structure. The material combination in composites provides properties unachievable for other materials - e.g. high ultimate tensile strength combined with elasticity or high stiffness along with vibration damping ability. Low density including corrosion resistance makes composite materials a good choice for many watercraft applications [26, 27]. Unlike the 'standard' materials, composites are prone to specific types of damage like delaminations [28, 29]. Delamination present in layered material can be completely invisible on the surface. Advanced NDT methods are needed to detect layer separation. The ultrasonic testing is widely used for composite NDT. However, especially for materials with complex geometry, ultrasonic testing can be slow and sometimes very hard to implement. 
Currently used NDT techniques in industrial applications are often quite expensive in terms of overall cost of the system (testing procedure, testing duration, equipment) and its operation (labor, expert staff) [30, 31, 32, 33]. Therefore, it is imperative to introduce new robust NDT techniques for composite damage detection allowing for time and cost reduction [34]. The aim of the research was to prove the effectiveness of low cost vibrothermography test system for delamination type defect detection in composite plates.

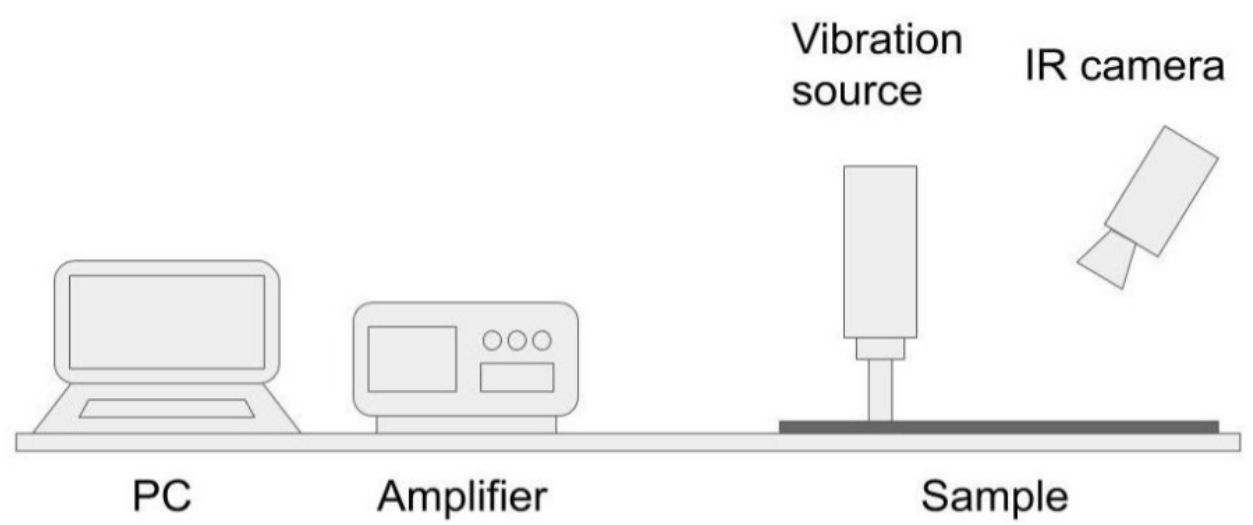

Fig 14. Vibrothermography test rig - schematic

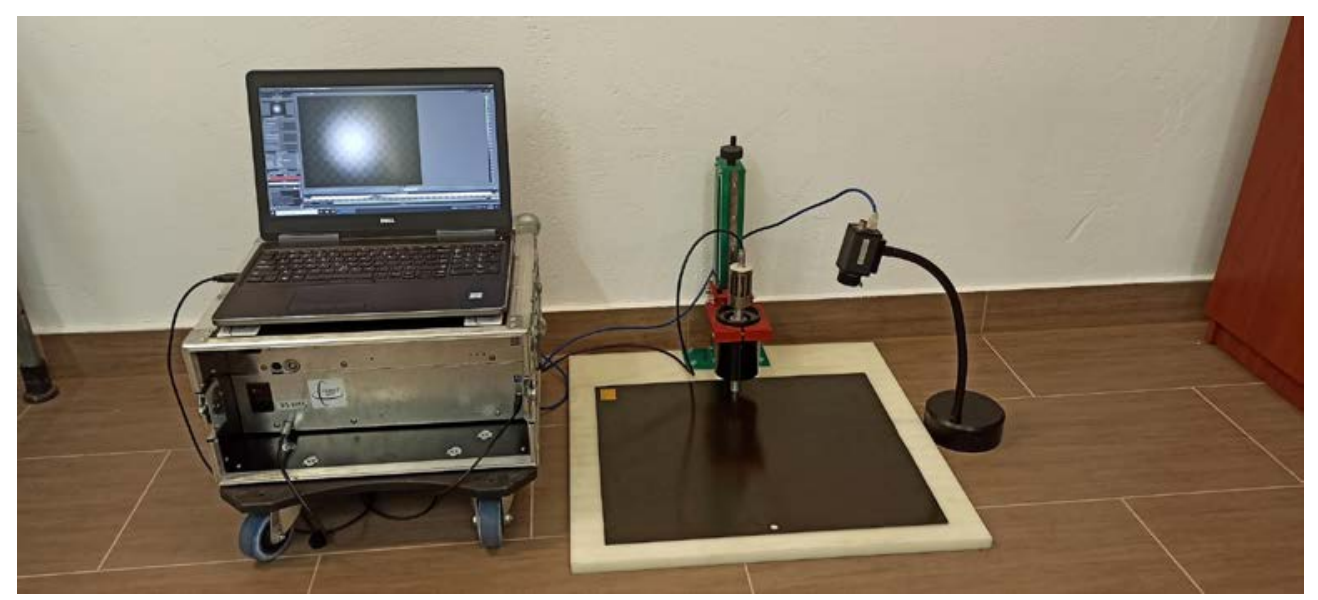

Fig 15. Vibrothermography test rig - real photo (AGH UST Kraków, Poland)

Vibrothermography is an active thermography method, which utilizes mechanical excitation [35]. The electromechanics vibrational source delivers energy into the samples' structure in the form of mechanical waves. The mechanical wave propagates through the sample. If the wave encounters internal flaws (e.g. closed cracks or delamination) a friction phenomenon occurs. Friction between surfaces of delamination produces heat, which has to be dissipated. Created heat is conducted to the object surface, which can be detected by an IR camera [36-37]. 
The experimental vibrothermography setup developed at AGH UST is shown in Figures 14 and 15. The system consists of a low-cost IR camera (FLIR A35sc), vibration source with amplifier and PC with relevant software. The vibration source operates up to 500W input power and produces $35 \mathrm{kHz}$ acoustic waves. The IR camera captures $256 \times 312$ frames with $60 \mathrm{~Hz}$ rate.

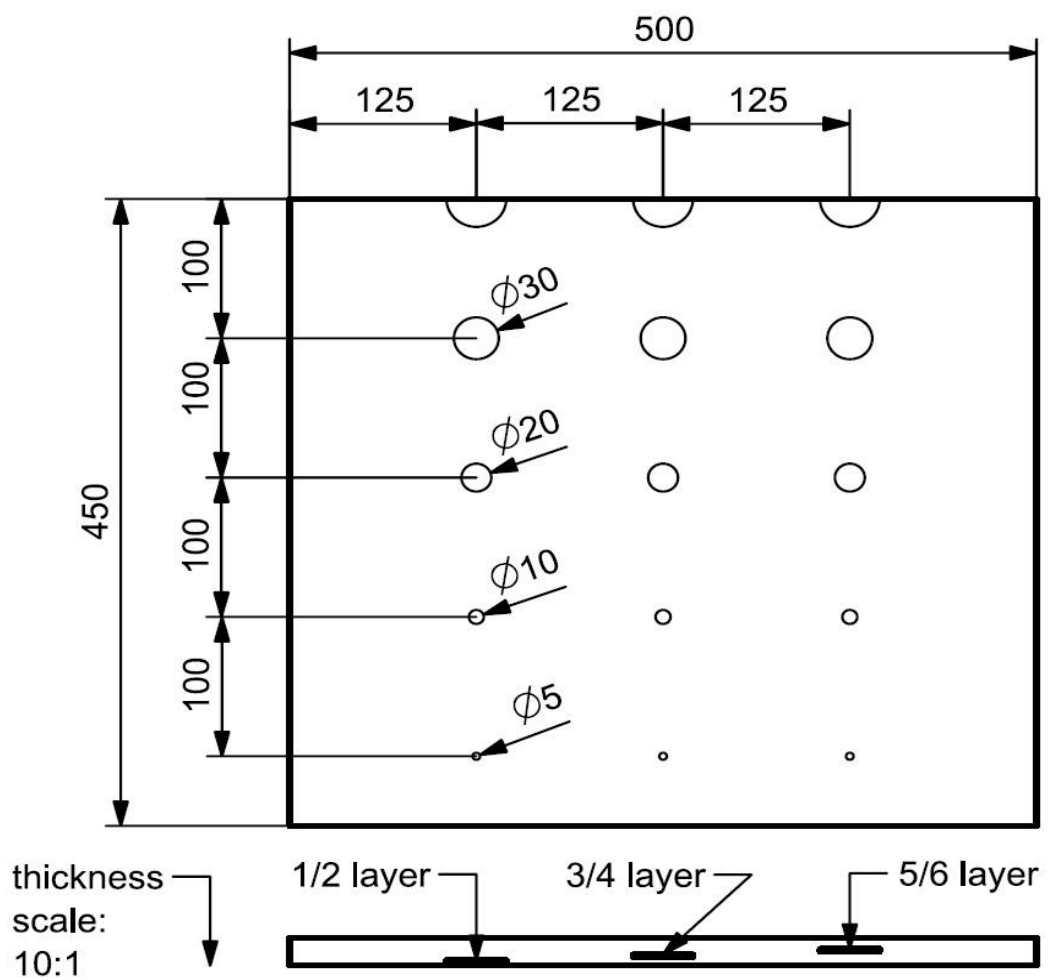

Fig 16. Tested sample - composite laminate with artificial defects (Teflon spacers) which mimic delaminations

Figure 16 shows the tested sample made of carbon fiber prepreg laminate 985-GF3070PW. The sample dimensions were $450 \times 500 \mathrm{~mm}$ and about $2 \mathrm{~mm}$ thick. The laminate has 10 layers of $0.2-0.24 \mathrm{~mm}$ thickness each and orientation as follows $0^{\circ} / 90^{\circ} / 0^{\circ} / 90^{\circ} / 0^{\circ} / 0^{\circ} / 90^{\circ} / 0^{\circ} / 90^{\circ} / 0^{\circ}$. It is important to note that the two middle layers have the same orientation, while the remaining layers make the whole laminate symmetrical. Between a set of chosen layers, Teflon spacers of different diameters were introduced during the manufacturing process. The purpose of Teflon spacers was to mimic delaminations. The advantage of this approach is that the artificially introduced delaminations have a well-known size and position. Therefore, the experiments were performed in controlled conditions.

The experiments were performed on composite plate using the following settings: vibration source was operating at $500 \mathrm{~W}$ and generated $35 \mathrm{kHz}$ waves. The excitation time was equal to 1s while the IR sequence was 32 seconds long (allowing capture of the whole excitation/propagation phase). The camera frame rate was equal to $60 \mathrm{~Hz}$. 


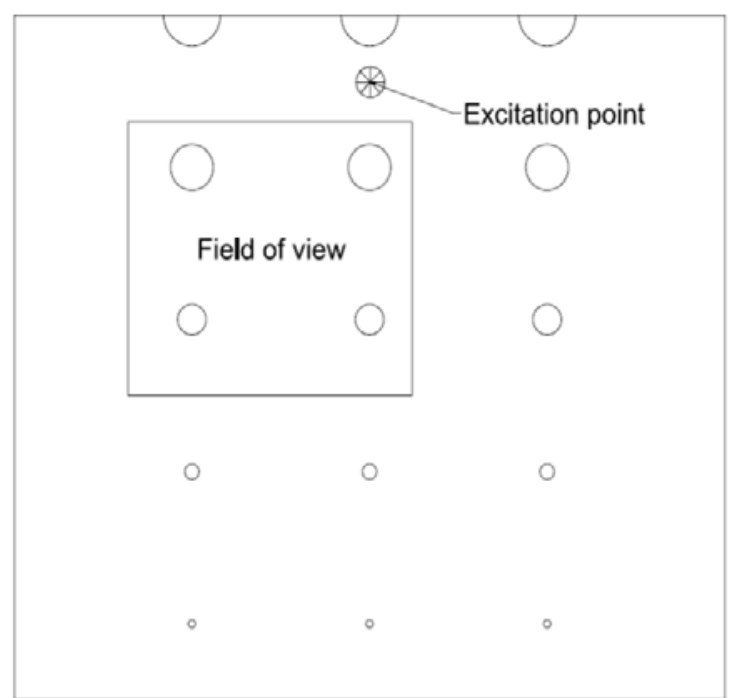

Fig 16. Test procedure - field of view

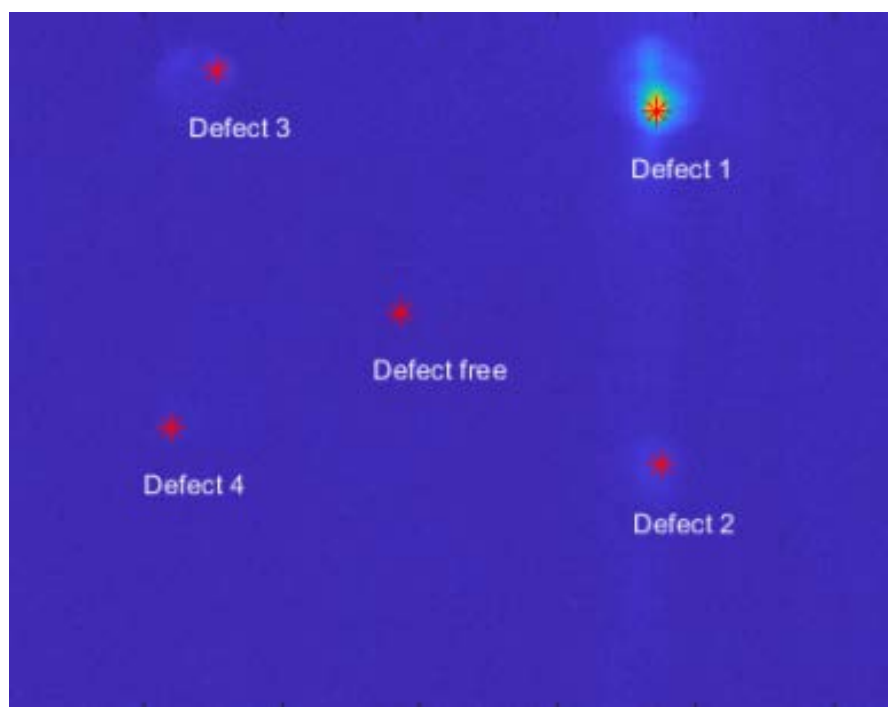

Fig 17. Experimental results - example frame

The Figures 16 and 17 shows IR camera field of view and frame corresponding to the end of excitation phase, when peak temperature increase was usually observed. Markers Defect 1 to Defect 3 corresponds to the pixels with visible highest temperature increase (for each delamination). The Defect 4 marker corresponds to the location of one of the defects. In this situation no obvious temperature increase was observed. Marker 'Defect free' according to its name represents the healthy area of the sample and was used as a reference. 


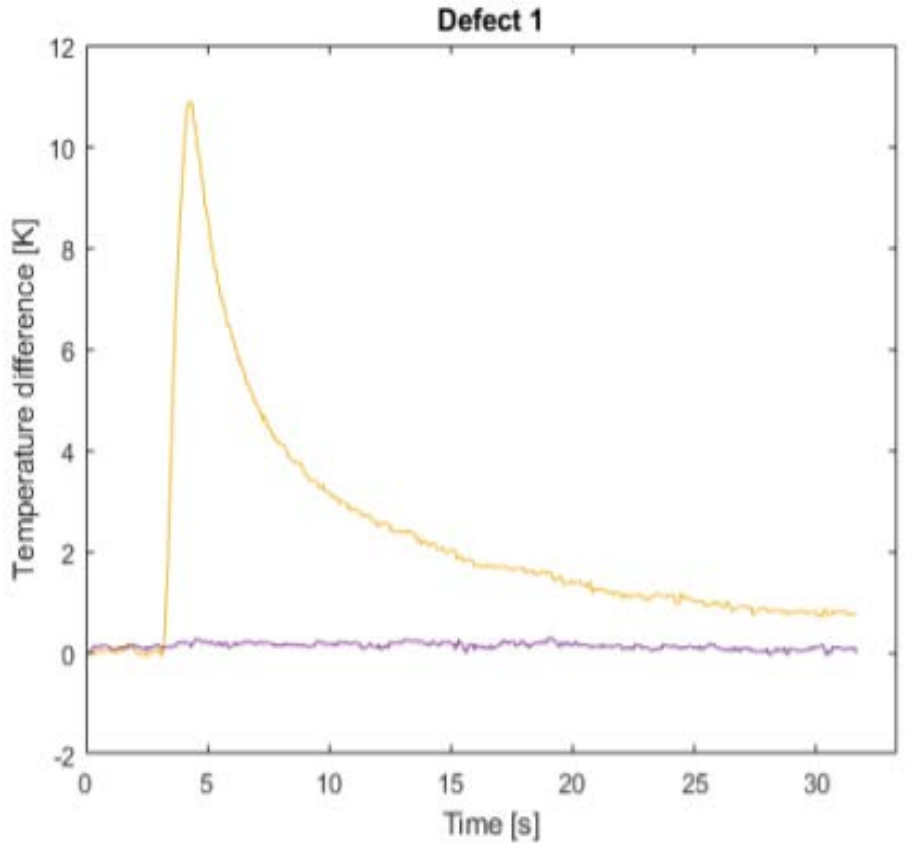

Fig 18. Experimental results - time plot for Point 1

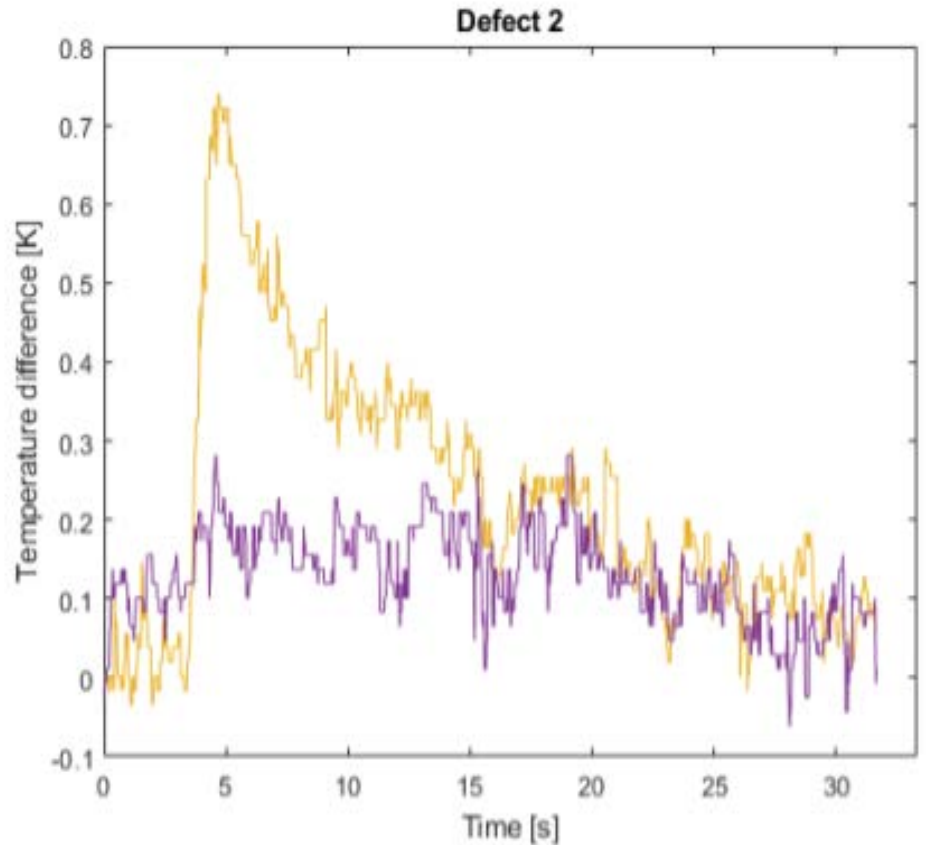

Fig 19. Experimental results - time plot for Point 2 


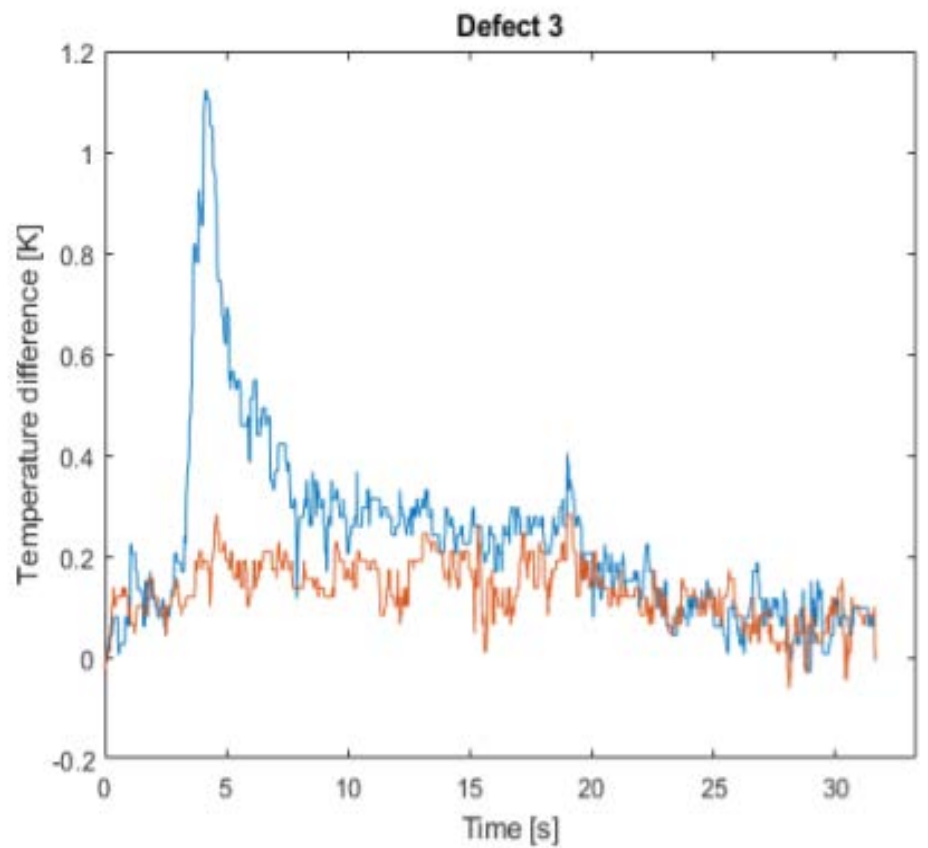

Fig 20. Experimental results - time plot for Point 3

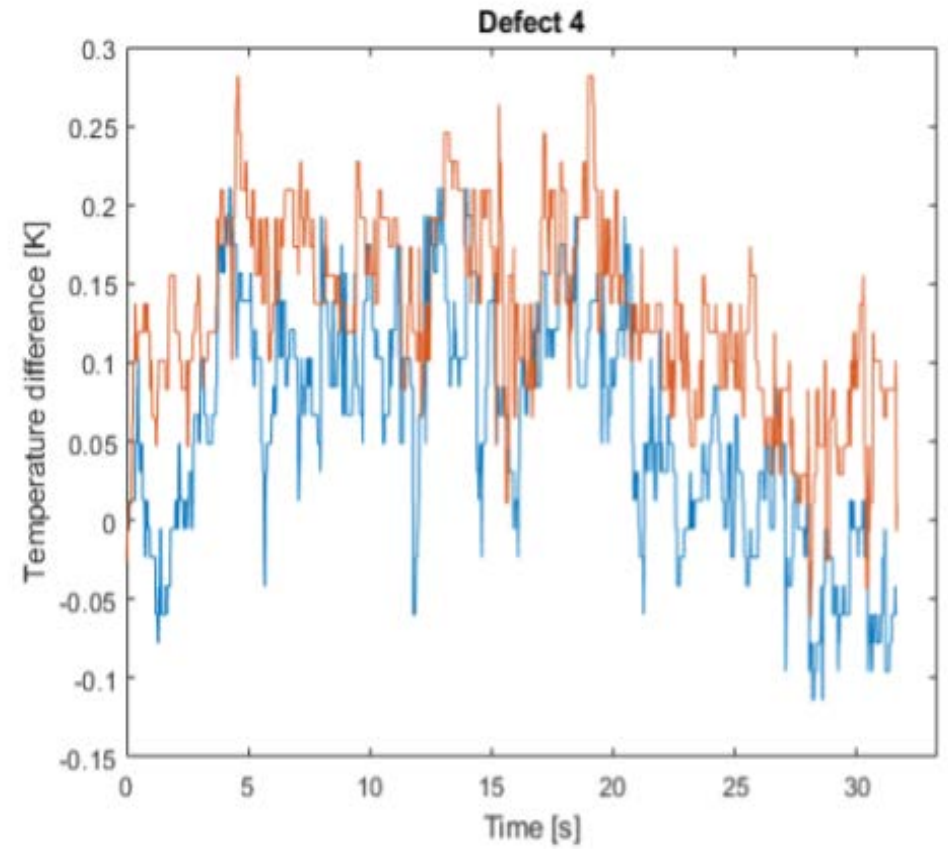

Fig 21. Experimental results - time plot for Point 4 
Presented research proves the effectiveness of low cost vibrothermography test system for detecting delamination-type defects in composite plates. The overall cost of the system is below 10,000 Euro; thus, it can be considered affordable. The relatively simple setup for vibrothermography testing makes this technique very promising for various applications, where fast, reliable and robust testing procedure is required.

\section{CONCLUSION}

Thermography is an effective tool to study various cold technology applications. The article reviewed some of the applications studied and tested by the authors.

Rashid et al. [9] studied thermal conductivity and heat transfer coefficient for fresh water and sea water ice using IR thermography in conjunction with three-dimensional finite difference solution of the heat equation. In this work, thermal conductivity and heat transfer coefficient were found for freshwater and seawater ice. The results revealed the difference in the properties. The results were found to be in close agreement with the literature.

Marine ice thickness is also measured with the help of thermography. The discussed work of Rashid et.al [16] is a laboratory-scale setup to measure marine ice thickness. The described methodology can be applied towards de-/anti-icing setups. The method described is based on measuring the average surface temperatures of the marine ice. Infrared thermography (IRT) is used to measure the thermal response of ice when subjected to active heating. These tests were performed at various controlled climatic conditions. The surface temperature profiles of marine icing samples were recorded with a calibrated high definition infrared camera. The results show distinct thermal profiles for different ice thicknesses (5, 10 and $15 \mathrm{~mm}$ ).

Estimation of Relative Required Insulation IREQ of clothes with thermography is also discussed in this paper. This study done by Tanveer et.al. [23] presents an estimate of thermal insulation (IREQ) of different types of thermal clothing. The results clearly showed the difference between the insulation ability of sweaters, summer jackets and winter jackets.

The fourth case presents the tensile testing of steel samples with IR thermography. In Stange et.al.[24] work it was noticed that for steel samples, their tensile strength increases by reducing the temperature and their surface was about $20-25^{\circ} \mathrm{C}$ warmer at the time of failure irrespective of temperature.

The fifth case presents the low-cost IR based system for nondestructive testing of composite materials. The composite plate with four artificially introduced delaminations was tested with vibrothermography test system. The research proves that even the low-end Flir A35sc infrared camera can be successfully used for fast and robust damage detection in composite materials. The overall cost of the system was below 10000 Euro, which makes it promising for low-volume production, where more advanced and expensive solutions are usually economically unjustified.

\section{REFERENCES}

[1] Gaussorgues, G.C.S., Infrared Thermography, 1994, Chapman and Hall.

[2] Ayele, Y.Z., Barabadi, A., Risk based inspection of offshore topsides static mechanical equipment in Arctic conditions, IEEE International Conference on Industrial Engineering and Engineering Management (IEEM), 2016, pp. 501-506.

[3] Lozowski, E., P, S.K., Makkonen, L., Computer simulation of marine ice accretion. Philos. Trans. R Soc, 2000, A 811-2845. 
[6] Wan, Z., 1999, MODIS (Moderate Resolution Imaging Spectrometer) UCSB Emissivity Library, University of California, Santa Barbara.

[7] EN-342, 2008, Protective clothing - Ensembles and garments for protection against cold, British Standard: Technical Committee PH/3, UK.

[8] ISO-11079, Ergonomics of the thermal environment-Evaluation of Cold Environments, Determination of Required Clothing Insulation, IREQ, 2007 International Organization for Standardization, Geneva.

[9] A. Nowick, Internal friction in metals, Progress in Materials Science, 1953, vol. 4, pp. $60-62$.

[10]C. Zener, General theory of thermoelastic internal friction, Internal Friction in Solids, 1938, vol. 53, pp. 90-99.

[11] Rashid, T., Khawaja, H. A., Edvardsen, K. Determination of thermal properties of fresh water and sea water ice using Multiphysics analysis, The International Journal of Multiphysics, 2016, 10(3): pp. 277-291.

[12] Rashid, T., Khawaja, H. A., Edvardsen, K., Mughal, U. N. Infrared Thermal Signature Evaluation of a Pure Ice Block, in Sensorcomm, International Academy, Research and Industry Association (IARIA), 2015, Venice, Italy.

[13] Moran, M.J., Introduction to Thermal Systems Engineering: Thermodynamics, Fluid Mechanics, and Heat Transfer, 2003, Wiley.

[14]Fukusako, S., Thermophysical properties of ice, snow, and sea ice, International Journal of Thermophysics, 1990, 11(2): p. 353-372.

[15] Leyli, A et al. Multiphysics Study of Forced Convection Conjugate Heat Transfer (CHT) Problem. The International Journal of Multiphysics, 2019, 13(3), ISSN 2048-3961, pp. 215- .

[16] Rashid, T., Khawaja, H. A., Edvardsen, K. Determination of Thermal Properties of Fresh Water and Sea Water Ice using Multiphysics Analysis, The International Journal of Multiphysics, 2016, 10 (3), pp. 277 - 291, ISSN 1750-9548.

[17] Rashid, T., Khawaja, H. A., Edvardsen, K., Mughal, U. N. Infrared Thermal Signature Evaluation of a Pure and Saline Ice for Marine Operations in Cold Climate, Sensors \& Transducers Journal, 2015, 194 (11), pp. 62-68, ISSN: 2306-8515.

[18] Rashid, T., Khawaja, H., Edvardsen, K. Measuring Thickness of Marine Ice Using IR Thermography, Cold Regions Science and Technology, 2018, ISSN 0165-232X.

[19] Khawaja, H. A et al. Multiphysics Simulation of Infrared Signature of an Ice Cube, The International Journal of Multiphysics, 2016, 10 (3), pp. 291-302, ISSN 1750-9548.

[20]FLIR ${ }^{\circledR}, 2015$, T1030sc, FLIR ${ }^{\circledR}$ Inc.

[21]FLIR®, 2017, FLIR Research IR Max, FLIR® Inc.

[22] Rashid, T., Khawaja, H.A., Edvardsen, K. Review of marine icing and anti-/deicing systems. J. Mar. Eng. Technol, 2016, 15, pp. 79-87.

[23] Moran, M.J. Introduction to Thermal Systems Engineering: Thermodynamics, Fluid Mechanics, and Heat Transfer, 2003, Wiley.

[24] Ahmad, $\mathrm{T}$ et al. Study of Wind Chill Factor using Infrared Imaging. The International Journal of Multiphysics, 2016, 10(3), pp. 325-341, ISSN 2048-3961.

[25] Ahmad, T., Rashid, T., Khawaja, H. A., Moatamedi, M. Study of the required thermal insulation (IREQ) of clothing using infrared imaging, The International Journal of Multiphysics, 2017, 11(4), pp. 413-426, ISSN 1750-9548. 
[25] Stange, E., Andleeb, Z., Khawaja, H., Moatamedi, M. Multiphysics Study of Tensile Testing using Infrared thermography. The International Journal of Multiphysics, 2019, 13(2): pp. 191 - 202.

[26] Ju Feng Special Steel Co., Ltd, 2019, date accessed on 5-06-2019. https://www.jfssteel. com/en/steelDetail/DIN-9SMn28/DIN-9SMn28.html.

[27] Kwon, Y., Conner, R. Low velocity impact on polymer composite plates in contact with water. The International Journal of Multiphysics, 2016, 6(3), pp. 179- , ISSN 2048-3961.

[28] Avachat, S., Zhou, M. Effect of core density on deformation and failure in sandwich composites subjected to underwater impulsive loads. The International Journal of Multiphysics, 2016, 6(3), pp. 241-265, ISSN 2048-3961.

[29] Kwon, Y., Owens, A., Kwon, A. Experimental Study of Impact on Composite Plates with Fluid-Structure Interaction. The International Journal of Multiphysics, 2016, 4(3), pp. 259-271, ISSN 2048-3961.

[30] Strand, C., Andleeb, Z., Khawaja, H., Moatamedi, M. Multiphysics Impact Analysis of Carbon Fiber Reinforced Polymer (CFRP) Shell. Materials Science Forum, 2019, 13, pp. 115-120.

[31]Bennoud, S., Zergoug, M. Simulation of Cracks Detection in Tubes by Eddy Current Testing. The International Journal of Multiphysics, 2016, 10(4), pp.417-428, ISSN 20483961.

[32] Bennoud, S., Zergoug, M., Allali, A. Numerical simulation for cracks detection using the finite elements method. The International Journal of Multiphysics, 2016, 8(1), ISSN 2048-3961, pp. 1-9.

[33] Mańka, Michał, et al. PZT based tunable Interdigital Transducer for Lamb waves-based NDT and SHM. Mechanical Systems and Signal Processing, 2016, 78: 71-83.

[34] Mańka, Michał, et al. Tunable interdigital transducers made of piezoelectric macro-fiber composite. Smart Materials and Structures, 2016, 25.11: 115022.

[35] Roemer, J. Laser spot thermography - scanning mode. The International Journal of Multiphysics, 2019, 13(1), pp. 81-90, ISSN 2048-3961.

[36] Roemer, J., et al. Nondestructive Testing of Ceramic Hip Joint Implants with Laser Spot Thermography. Archives of Metallurgy and Materials, 2017, 62.4: 2133-2139.

[37] Pieczonka, L., \& Szwedo, M. Vibrothermography. In T. Stepinski, T. Uhl, \& W. J. Staszewski (Eds.), Advanced Structural Damage Detection: From Theory to Engineering Applications, 2013, pp. 233-261, Wiley.

[38] Pieczonka, L., Aymerich, F., Brozek, G., Szwedo, M., Staszewski, W. J., \& Uhl, T, Modelling and numerical simulations of vibrothermography for impact damage detection in composites structures. Structural Control and Health Monitoring, 2013, 20(4), 626638. 
